TAO, Vol. 15, No. 5, 1019-1033, December 2004

\title{
An Intensive Mongolian Cyclone Genesis Induced Severe Dust Storm
}

\author{
Jing-Tao Liu ${ }^{1}{ }^{1}{ }^{*}$, Xue-Gong Jiang ${ }^{1}$, Xin-Jiang Zheng ${ }^{2}$, Ling Kang ${ }^{1}$, and Fu-Yu Qi ${ }^{1}$
}

(Manuscript received 12 February 2003, in final form 30 April 2004)

\begin{abstract}
In this paper, a severe dust storm which occurred in northern China is presented and its associated physics investigated. The main sand source regions of this storm were from the Badanjilin Desert in western Inner Mongolia (IM), western Hunshandakend sand lands and the Gobi Desert in southern Mongolia. This dust storm process was a typical cyclonic dust storm, induced mainly by intensive development of a Mongolian cyclone rather than any other weather system. The formation of the strong surface winds was caused not only by the intensive development of a cyclone, and the passage of a cyclonic cold front, but also by a strong meso-scale pressure gradient. The former closely accorded with the severe dust storm while the latter induced the severe prefrontal dust storm. The dust raising mechanism could be described in the following manner: after obtaining much momentum from strong surface winds, the dust was raised upward by strong turbulence in the PBL and then by the systemic ascending motion of a cyclonic system. In addition, divergence-pumping in the upper troposphere indirectly transplanted dust upward.
\end{abstract}

(Key words: Dust storm, Physics causing, Mongolia Cyclone, Upper level jet)

\section{INTRODUCTION}

As a disastrous weather process, a severe dust storm can produce remarkable damage to construction, electrical facilities, our ecological environment and so on, as well as being menacing to human health. There have been many studies of dust storm mechanisms such as

\footnotetext{
1 Inner Mongolia Meteorological Observatory, Huhhot, China

2 National Satellite Meteorological Center, Beijing, China

* Corresponding author address: Prof. Jing-Tao Liu, Inner Mongolia Meteorological Observatory, Huhhot, China; E-mail: lit@public.hh.nm.cn
} 
Barenblatt (1974) who studied physical rules of dust storms theoretically. And in recent years, climatologic and occurrence mechanisms of dust storms has aroused more attention and research interest. This attention and interest can be widespread as most dust storm processes occurring in China result in dust particles being transported to Korea, Japan and the western Pacific. Fang compiled the "China Dust Storm Study", in which data from dust storms in recent years were collected (Fang 1997). By analyzing synoptic systems of dust storms in Arizona, US from 1965 to 1980, Brazel concluded that a dust storm could be induced through the following four synoptic systems: (1) frontal forcing, (2) thunderstorms, (3) tropical turbulence and (4) an upper level cut-off low. In addition, many researchers suggest that cold front and dry squall lines (Fang 1997; Xu 1979; Liu 1996; Hu 1996) are typical weather systems causing dust storms. Jiang (2003) conducted a numerical study on the synoptic conditions affecting the formation of dust storms, such as strong surface winds, topography, stratification and mixed layer. Liu (2004) conducted a composite comparative study of the dust events in Taipei and Beijing and indicated the different weather characteristic between them. Wang (2004) revealed the aerosol characterization in the dust storm process attacked Taiwan's northern tip. Yuan (2004) investigated the mass concentration and size distribution of atmospheric aerosols collected at Pencadores Islands during Asian dust storm periods in the years of 2001 and 2002. Lin (2004) studied the climatology of long-range transport of Asian dust and its aerosol characterization. Chen (2004) conducted a simulation on the events of dust incursion over Taiwan and gave a complete picture of these transport patterns.

In this paper, a study on a large-scale severe dust storm process, which occurred in most parts of northern China, especially in Inner Mongolia (IM) and lasted from April 6 to 7, 2001 with unprecedented intensity (in five stations the surface visibility was $<50 \mathrm{~m}$, Liu 1998), was conducted. Satellite remote sensing images, climate data and routine meteorological data were used to study the relationship between an arid climatic background, intensive development of a Mongolian cyclone, the formation of the upper level jet and a severe dust storm. Remarkably, the relationship between the development of a Mongolian cyclone and formation of a dust storm is proposed for the first time.

\section{THE SAND SOURCE AND ARID CLIMATE BACKGROUND}

\subsection{Sand Source}

This area of northern China has many features conducive to sand storms being an arid to semi-arid climatic area with a harsh ecological environment. From west to east, there is the Badanjilin Desert, Maowusu sand lands and the Hunshandake sand lands of IM, respectively (see Fig.1). For the severe dust storm of April 6 to 7, 2001, the sand raised from Badanjilin Desert and Hunshandake sand lands contributed to the formation of the dust storm (compare Fig. 1 and Fig. 2). In addition, over recent decades, both grass and farm lands of the region have been subject to severe desertification due to climatic warming, decreasing rainfall per year post 1950's, destructive human activities, such as over herding, farming on grasslands and extreme deforestation. These processes have led to the stability of soil structures in the region being severely diminished providing abundant sandy materials for forming dust storms. 
Added to the sands of these regions are those of Mongolia where broad desertification is also occurring.

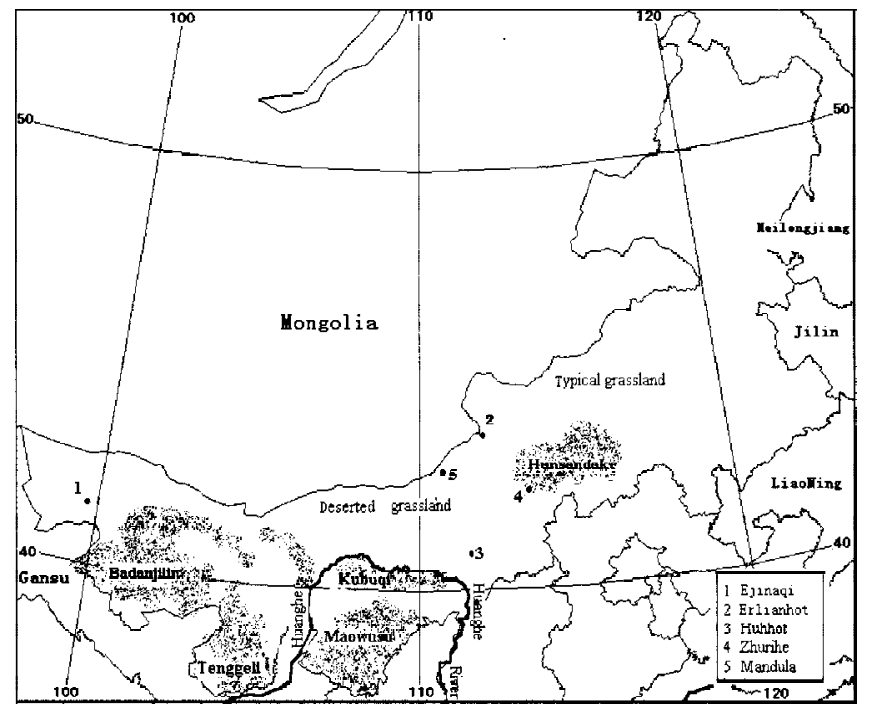

Fig. 1. The terrain, desert distribution and some stations quoted in this paper around Inner Mongolia.

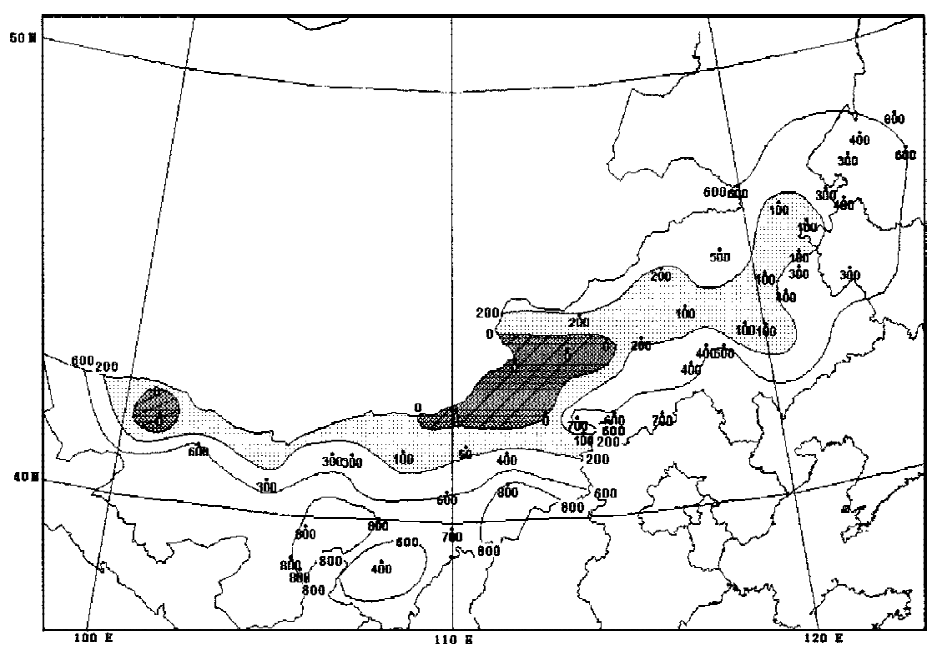

Fig. 2. The visibility distribution of the dust storm occurring in Inner Mongolia, Jilin and Heilongjiang regions on April 6 - 7, 2001 (Unit m, interval 200). The shaded areas are the black storm regions (visibility $<50 \mathrm{~m}$ ). The shadow area is the severe dust storm region (visibility $\leq 200 \mathrm{~m}$ ). 


\subsection{Arid Climatic Background}

Over the past two years, departure from normal annual precipitation in most regions of IM was $-25 \%$ to $-50 \%$, which resulted in denuded soil surfaces. In February and March of 2001 , average rainfall was off some $40 \%-100 \%$. Continuous drought conditions with no rainfall for almost 90 days in western IM and a rapid increase in temperature led to remarkable soil moisture loss. In addition, after some 10 minor dust storm episodes, the top soil had became dry and loose resulting in a $5-15 \mathrm{~cm}$ dry soil layer. These conditions were ripe for a major dust storm.

\section{RESULTS AND DISCUSSION}

\subsection{The Spatial and Temporal Evolution of The Dust Storm}

At 1400LST (LST, Beijing local time) on April 6, cold Siberian air began invading Xinjiang province (North-West China) and induced fly-sand (a kind of weather phenomena). In the mean time, observed surface wind speed in Gansu Province was larger than $14 \mathrm{~m} \mathrm{~s}^{-1}$. At 0800LST, the cold air reached western IM, carrying fly-sand over a large area. By 1400LST, the dust storm had strengthened and expanded to the middle regions of IM with strong surface winds greater than $18 \mathrm{~m} \mathrm{~s}^{-1}$ and horizontal visibility from $200 \mathrm{~m}$ to $300 \mathrm{~m}$. By 2000LST, the dust storm in western IM started to weaken and eventually petered out, while the dust storms in northern IM continued to strengthen, with visibility at less than $200 \mathrm{~m}$. During the period, 1600LST, April 6 to 0200LST, April 7, the dust storm had reached its maximum strength and formed a black storm with visibilities decreased to $0 \mathrm{~m}$ at 5 meteorological stations of the middle to northern regions in IM. At 0800LST, April 7, the dust storm in northern IM had stopped, but the dust storm expanded to eastern IM where visibility had been reduced to 50 to $300 \mathrm{~m}$. By 1400LST, April 7, the dust storms in eastern IM maintained, while dust storms began to affect Heilongjiang and Jilin province. Not until 2000LST on April 7, did the 40-hour dust storm terminate after affecting 7 provinces in northern China as well as the southern part of Mongolia.

This dust storm process induced severe damage to the environment, and agriculture, disrupted transportation and affected people's health. According to incomplete statistics, about $95 \%$ of seeded wheat on 23000 acres in West-North IM was blown away. In northern IM 30, 783 cubs died and about 30000 head of livestock were lost, while 4310 livestock barriers and protective facilities were damaged. In the Saihantala city (north IM), some reports of loss of human life were made as people were unable to receive immediate medical assistance after being injured in some way by the dust storm. In addition, Qiqihar city airport was closed for 8 hours.

Figure 2 indicates that the dust storm center was located in the middle to northern sections of IM with some stations in the region reporting zero visibility. The station numbers and respective visibilities are listed in Table 1 . The data indicate that this dust storm process was very intense and influenced a broad area. Analysis of images afforded by the Geographical Information System (GIS) and Satellite Remote-Sensing (SRS) reveal that the storm covered 
Table 1: Station numbers with different surface horizontal visibility on April 67 of 2001.

\begin{tabular}{|c|c|c|c|c|}
\hline Grade & $\mathrm{V} \leq 50 \mathrm{~m}$ & $50 \mathrm{~m}<\mathrm{V} \leq 200 \mathrm{~m}$ & $200 \mathrm{~m}<\mathrm{V} \leq 500 \mathrm{~m}$ & $500 \mathrm{~m}<\mathrm{V} \leq 1000 \mathrm{~m}$ \\
\hline Stations & 7 & 13 & 14 & 15 \\
\hline
\end{tabular}

an area of about 1030000 square kilometers in China.

The severe dust storm area (visibility $<200 \mathrm{~m}$ ) expanded from west to east between $42^{\circ} \mathrm{N}$ to $46^{\circ}$ N. Comparing Figs. 2 and 3, it can be seen that the formation of such an area is closely related to the movement of a Mongolian cyclone. Note that this is quite different from the cold front dust storm areas extending from the northwest to southeast (Qian 1997), and different again to small-scale dust storm areas caused by a squall line.

\subsection{The Intensive Development of A Mongolian Cyclone}

This large-scale severe dust storm was closely related to the intensive development of a Mongolian cyclone. The formation, development and movement of the cyclone are presented as follows:. At 0200LST, April 5 a cyclone formed on the western side of the Altai-Sayan Mountain Complex centered at $51^{\circ} \mathrm{N}, 82^{\circ} \mathrm{E}(1003 \mathrm{hPa})$. It followed a path south-eastward until a day later it centered at $\left(49^{\circ} \mathrm{N}, 100^{\circ} \mathrm{E}\right)$ by now its central pressure had dropped to 995 $\mathrm{hPa}$. At the same time, a cyclonic cold front had reached Xinjiang and Gansu provinces causing strong surface winds that lifted sand into the air. By 0800LST of April 6, the Mongolian
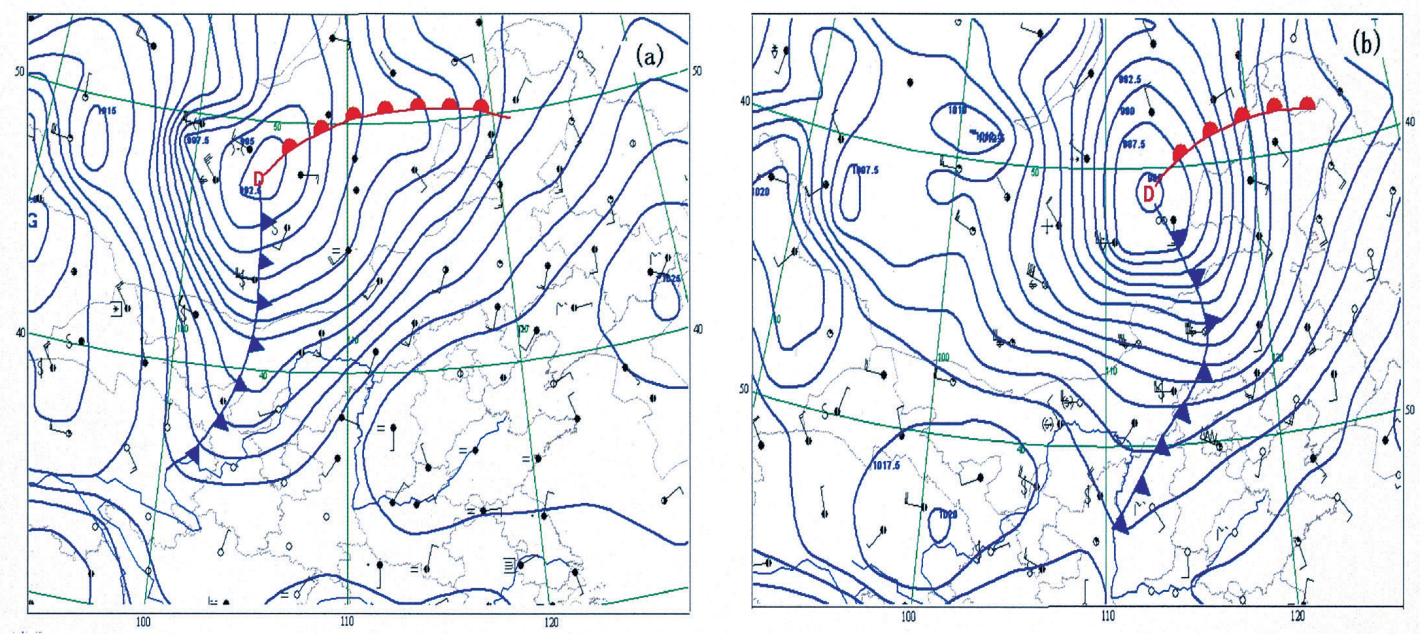

Fig. 3. The surface weather charts at 0800LST April 6, 2001 (a) and 2000LST, April 6, 2001 (b). The data came from the routine surface meteorological data. 
cyclone had moved to Wulanbatuo (the Mongolian capital) with central pressure at $991 \mathrm{hPa}$ (See Fig. 3a, based on IM Meteorological observatory weather chart data). After the cyclonic cold front passed, a large-scale fly-sand was observed in western IM. Then, the cyclone moved eastwards along the zonal area $\left(48^{\circ} \mathrm{N}-50^{\circ} \mathrm{N}\right)$, resulting in a large-scale severe dust storm where the cyclonic cold front and secondary cold front passed. During the period from 2000LST (See Fig. 3b), April 6 to 0200LST, April 7, the Mongolian cyclone developed intensively with its central pressure decreasing $6 \mathrm{hPa}$. It then moved slowly for about $100 \mathrm{~km}$ (a mean movement speed of $246 \mathrm{~km} / 6 \mathrm{~h}$ ) resulting in a super severe dust storm in Xilinguole (in northern $\mathrm{IM}$ ), the visibility measured in three stations reached $0 \mathrm{~m}$. Clearly, the intensive development of the Mongolian cyclone caused strong surface winds and then induced the super severe dust storm. By 0800LST, April 7, the cyclone had become occluded; its center moved eastwards to $48.5^{\circ} \mathrm{N}, 118.5^{\circ} \mathrm{E}$ and its central pressure reached $977 \mathrm{hPa}$ (This record was not only the lowest central pressure in this process, but also the lowest of all 18 dust storms to have occurred from January to May of 2001), at this point the dust storm started to attack Heilongjiang and Jilin provinces. The dust storm area formed a semi-circle around the southern part of the cyclonic center behind the cold front. The facts above suggest that both the strength and scope of the dust storm were closely related to the intensive development and movement of the Mongolian cyclone. At 1400LST, April 7, the Mongolian cyclone began to weaken and died at 2000LST, April 7.

A comparison of the Mongolian cyclone dust storm and the dry squall line dust storm reveals the evident characteristics of the cyclone dust storm. Firstly, the dry squall line dust storm process sustained for only a short time (the dust storm on May 5, 1993 lasted $10 \mathrm{~h}$ ) while the time period for the Mongolian cyclone dust storm was very long at $40 \mathrm{~h}$ in this case. Secondly, the dominant winds were northwesterlies or northerlies during the dry squall line dust storm process (as above) while they were west or south-westerlies in this case. Thirdly, the strength of the dust storm reached a peak in the afternoon of the dry squall line process (as above, 1400 - 2000 LST) while it was at night (2000 - $0200 \mathrm{hLST})$ in the cyclone case indicating that surface heat was likely not very important in this case. These facts indicate that the intensive development of the Mongolian cyclone was the dominant factor causing the dust storm in this case.

Figure. 4 indicates that there were two dust storm zones related to the cold front and secondary cold front. From observational data, it can be determined that a dust storm usually occurs after cyclonic and secondary cold fronts in accordance with a strong surface wind area (Liu 1998). In this case, it is apparent some dust came from the Gobi desert in Mongolia and not just from IM. In additional, within the warm area of the cyclone (area A in Fig. 2), a severe dust storm appeared with a horizontal scale of about $300 \mathrm{~km}$. A horizontal visibility of $200 \mathrm{~m}$ was measured in Erlianhot and Zhurihe stations (Northern IM, see Fig. 1). It was formed by a meso-scale turbulence of pressure which was denoted in Fig. 4 (area A, will be discussed later). From Figs. 4 and 5 it is apparent that the Mongolian cyclone first developed to its maximal strength, and then occluded with dusts being raised to the occluded cyclone center by ascending cyclonic air. 


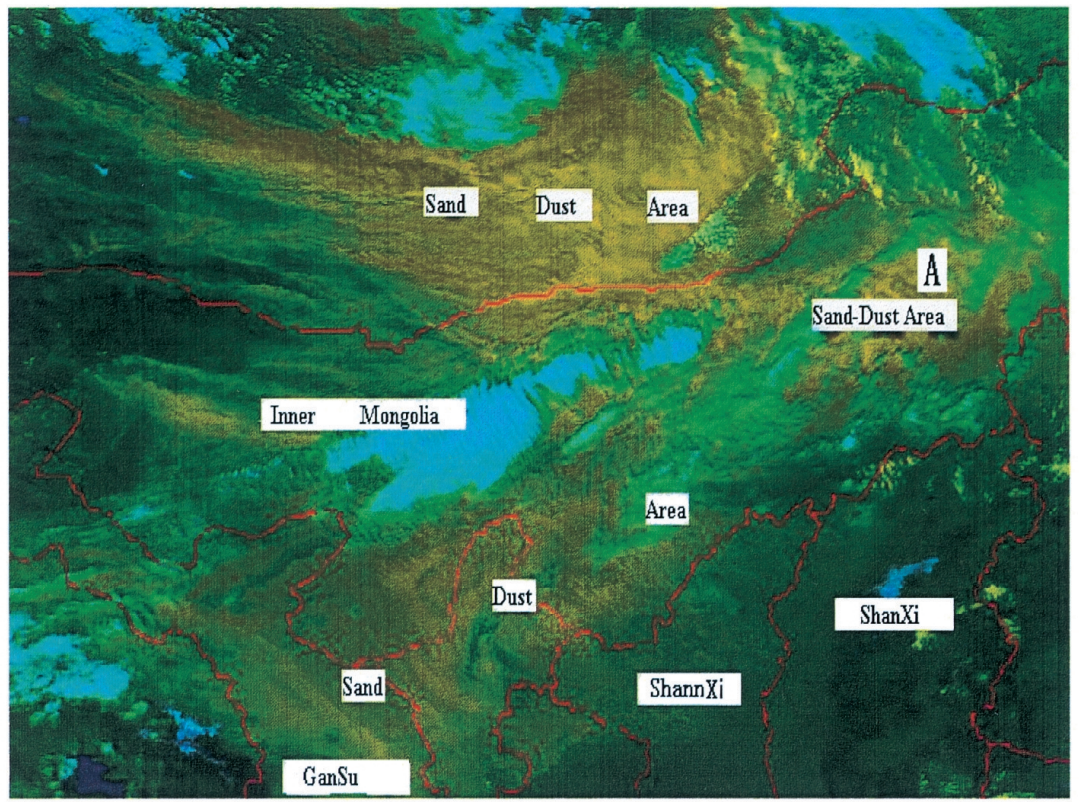

Fig. 4. The NOAA-16 satellite remote sensing image of the dust storm at 1400LST, April 6, 2001, the yellow zone is a dust storm area.

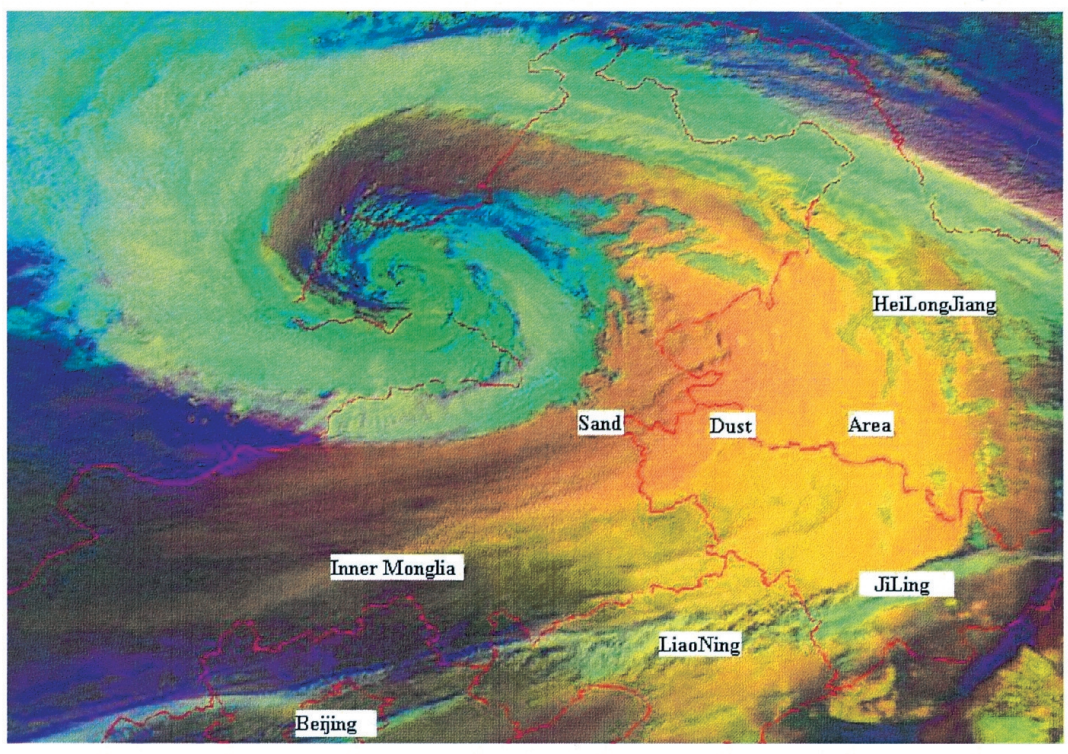

Fig. 5. The FY-1C satellite remote sensing image of the dust storm at 0800LST, April 7, 2001, the yellow zone is a dust storm area. 


\subsection{The Meso-scale Pressure Disturbance}

Figure 6 shows a meso-scale pressure turbulence (framed area) between the two stations in the warm area of the Mongolian cyclone. The pressure gradient maximum reached $7.5 \mathrm{hPa} / 60 \mathrm{~km}$ with a horizontal scale of $300 \mathrm{~km}$. The meso-scale pressure turbulence and the isallobar-line gradient in the warm area of the cyclone can be clearly seen from Fig. 6, and it could be related to activation of a strong cold front. The turbulence produced strong surface wind in Erlianhot and Zhurihe stations (surface wind speed was $16 \mathrm{~m} \mathrm{~s}^{-1}$ at 1400LST, April 6) inducing a severe dust storm (A area in Fig. 4). To confirm our argument that the severe dust storm in the warm area of the cyclone was created by meso-scale pressure turbulence rather than the dry squall line, we further analyzed the autographic records of the surface pressure, temperature, and humidity as well as wind in the two neighboring stations (Fig. 7a, Jiang 2003). The result indicated that these factors at the two stations did not characterize a "pressure nose" (squall line, Fig. 7b, Zhang 2003). However, it is clear that the change was related to the turbulence of a meso-scale low. Comparing the pressure, temperature and relative humidity, the meso-scale disturbance was warm and dry. The wind changed from W to WNW and the wind speed increased further when the cold front had passed. The meso-scale pressure disturbance also happened in the synoptic scale pressure field after the cold front passed.

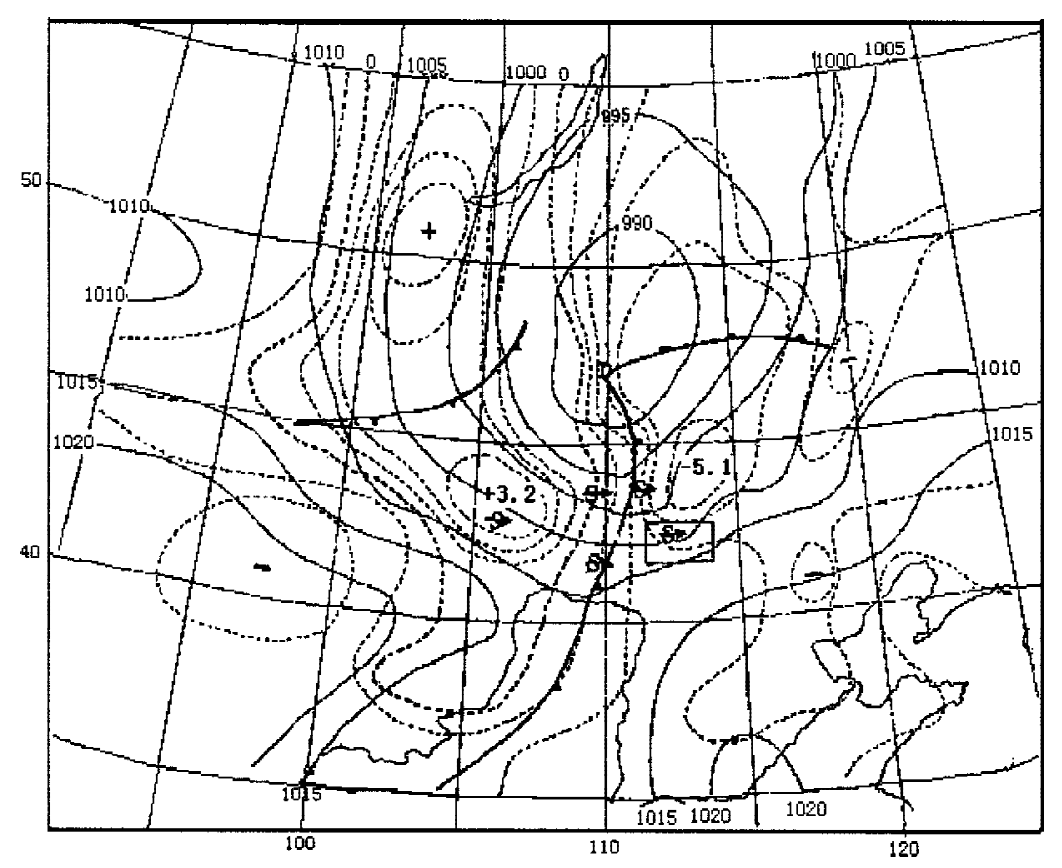

Fig. 6. The surface weather chart at 1400LST, April 6, 2001 (The solid line is pressure, and the dashed line represents the $3 \mathrm{~h}$ isallobars). 

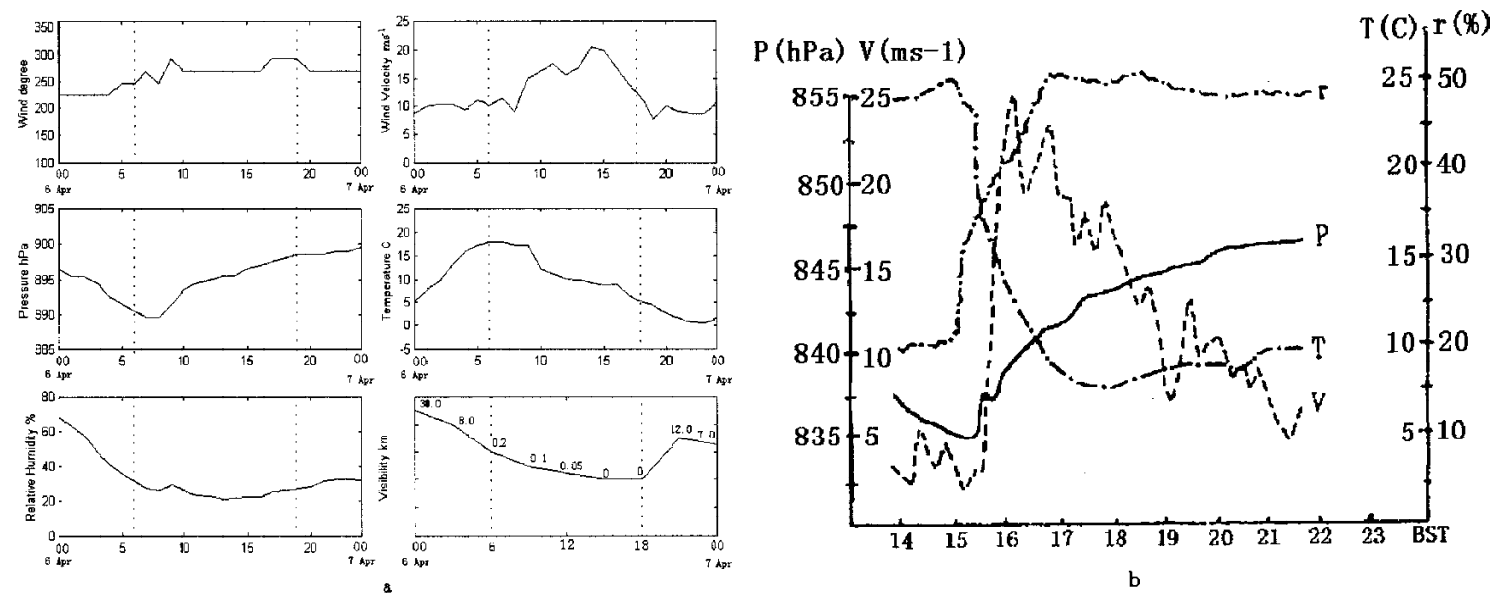

Fig. 7. (a) The evolution of surface meteorological factors (wind, wind speed, pressure, temperature and visibility) at Erlianhot station in this process (Jiang 2003). (b) The evolution of surface meteorological factors (wind, wind speed, pressure and temperature) in the dry squall line process on May 5, 1993 (Zhang 2003).

Comparing the two 3-hour allobaric centers of $-5.1 \mathrm{hPa}$ and $+3.2 \mathrm{hPa}$ in Fig. 6, one can see that a strong isallobar gradient was formed between the two centers. The severe dust storm occurred in the strong allobaric gradient area (at Mandula station in northern IM, the surface wind speed was as high as $22 \mathrm{~m} \mathrm{~s}^{-1}$, at 1400LST, April 6, 2001, while the horizontal visibility was close to $0 \mathrm{~m}$ ). Clearly, ageostrophic wind formed by the allobaric gradient played an important role in the formation of strong surface wind, which was one reason leading to the super severe dust storm (Wang 2000).

\subsection{Possible Dynamic Mechanisms}

Yao (1998) argued that dust must firstly obtain strong momentum from strong wind before it can be raised. A factor which can complete this raising mechanism is turbulence in the lower troposphere (PBL).

Based on results from Chen (1980), we calculated the Richardson number (Ri) for $850 \mathrm{hPa}$ $700 \mathrm{hpa}$ and $700 \mathrm{hPa}-500 \mathrm{hPa}$ from 0800LST, April 6 to 2000LST of April 7 at an interval of 12 h.

$$
R i=-\frac{R_{d} \Delta P}{\bar{P}}\left(\Delta T_{P}-\frac{A R_{d} \bar{T}}{C_{p d}} \frac{\Delta P}{\bar{P}}\right) /\left(\Delta u_{p}^{2}+\Delta v_{p}^{2}\right)
$$

where $R_{d}$ : dry air constant, $0.287 \mathrm{~J} \mathrm{~kg}^{-1} \mathrm{~K}^{-1} ; C_{p \mathrm{~d}}$ : special heat at constant pressure, $1005 \mathrm{~J} \mathrm{~kg}^{-1} \mathrm{~K}^{-1}$; 
$\Delta T_{p}=T_{700 h p a}-T_{850 h P a}\left(T_{500 h p a}-T_{700 h P a}\right), K ; \Delta P: P_{700 h p a}-P_{850 h P a}\left(P_{500 h p a}-P_{700 h P a}\right), \mathrm{hPa} ;$ $\Delta u_{p}: u_{700 h p a}-u_{850 h P a}\left(u_{500 h p a}-u_{700 h P a}\right), \Delta v_{p}: v_{700 h p a}-v_{850 h P a}\left(v_{500 h p a}-v_{700 h P a}\right), \mathrm{m} \mathrm{s}^{-1}$; $A$ : equivalent of work and heat, $0.239, \mathrm{Ca} \mathrm{Erg}^{-1} \mathrm{le}(-7) ; \bar{T}$ : average temperature at $850 \mathrm{hPa}$ and $700 \mathrm{hPa}, \mathrm{K} ; \bar{P}$ : average pressure at $850 \mathrm{hPa}$ and $700 \mathrm{hPa}, \mathrm{hPa}$.

Under dry weather conditions, turbulence is a dominant characteristic indicating convective conditions in the PBL (being different from the free atmosphere). Dust can be raised into the free atmosphere by strong turbulence in the PBL and then be raised continuously into the middle troposphere via systemic ascending motion. The $\mathrm{Ri}$ (non-dimensional number) is a parameter denoting turbulence strength in the PBL. When $\mathrm{Ri}<0.1$ the turbulence is strong while it is weak when Ri $>0.1$. In this case (Fig. 8) we can see the Ri of middle IM were less than 0.1 on 0800LST, April 6, which indicates that intense turbulence existed in the lower troposphere and contributed to the formation of the dust storm. At 2000LST, April 7, the Ri was less than 0.1 in eastern IM and western Heilongjiang and Jilin, in contrast, in mid and western IM where the dust storm had ended, Ri was greater than 0.1 ( not shown). In addition, calculations show that for almost the whole period of the dust storm, Ri is less than 0.1, which indicates that there was strong turbulence. At the end of dust storm, Ri were greater than 0.1 at 2000LST of April 7, indicating turbulence in the lower troposphere clearly weakened. This

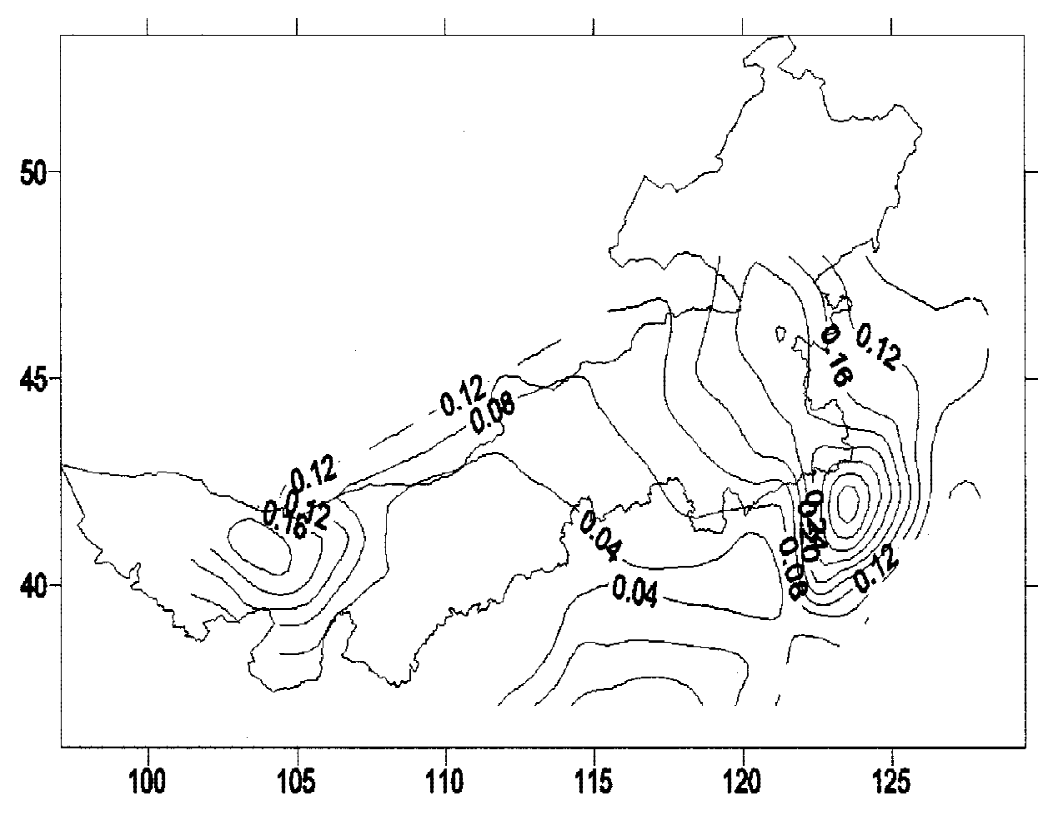

Fig. 8. The Ri (between $850 \mathrm{hPa} \sim 700 \mathrm{hPa}$ ) distribution around IM at 0800LST on April 6, 2001. 
evidence supports the notion that Ri has an obvious relationship to dust storm intensity. It is the main dynamic mechanism for raising sand in the lower troposphere. Ri is not only influenced by thermal stability, but also by the turbulence caused by vertical wind shear. Ri is probably a more useful parameter to analyze stability in the PBL, compared to the thermal stability parameter mainly being used (Qu 1994).

The cold front causing this dust storm did not result in precipitation. The cyclone moved at an average speed of $300-400 \mathrm{~km} / 6 \mathrm{~h}$ from 0200LST, April 6 to 0200LST, April 7. When it developed its maximum intensity (0200LST, April 7), movement speed began to decrease. By 0800LST, April 7, the speed was only $100 \mathrm{~km} / 6 \mathrm{~h}$. Speed started to increase again after the cyclone entered the Northeastern Plain. Strong ascending motion could have been induced by the cyclonic cold front. It was this motion that provided the force required to transport both sand and dust into the mid-troposphere. Huge amounts of sand and dust in the PBL can then be transported upward by ascending branches of secondary circulation from a cold front (Liu 1996).

During the whole dust storm process, the westerly upper level jet stream interaction with the polar front was very active. The core of the jet stream moved regularly eastwards according with the Mongolian cyclone and its cold front. From 0800LST, April 6 to 2000LST, April 7, the path of the jet core was at $300 \mathrm{hPa}$. This is shown in Fig. 9. The dashed line represents regions with the minimal visibility. The strength and the positions of the Mongolian cyclone are also indicated at 6-hour intervals.

At $0800 \mathrm{LST}$, April 6, the jet core was located above $94^{\circ} \mathrm{E}$, and the maximal wind speed was $46 \mathrm{~m} \mathrm{~s}^{-1}$. At 2000LST, April 6, it moved eastwards to $110^{\circ} \mathrm{E}$ at an increased speed of 700 $\mathrm{km} \mathrm{h}^{-1}$. During the period, a severe dust storm occurred on the left side of the movement path at $1400 \mathrm{LST}$. Locations $109^{\circ} \mathrm{E}$ and $112^{\circ} \mathrm{E}$ recorded minimal visibilities equal to $0 \mathrm{~m}$. With the increasing wind speed of the jet core and decreasing movement speed, the dust storm strengthened rapidly. At 2000LST, April 6, visibility decreased to $0 \mathrm{~m}$ over a large area of $200 \mathrm{~km} \times 150 \mathrm{~km}$ to the left-exit region of the jet. The jet core moved eastward along $42^{\circ} \mathrm{N}-43^{\circ} \mathrm{N}$ zone, which is consistent with the path of the Mongolian cyclone.

Our preliminary conclusions are as follows: Firstly, between the jet and the cyclone, the path and speed of the Mongolian cyclone are closely related to those of the upper-jet core. Its strength depended on the relative position between the cyclone center and the jet core. When the cyclone center was located at the left-exit region of the jet, far away from the jet core, the cyclone was in its developmental stage. When it was located at the same longitude as the jet core, cyclonic strength came to a peak. Later, when the cyclone center was to the west side of the jet core, the cyclone started to weaken. Secondly, between the dust storm and the jet, a super dust storm occurred at the left-exit region of the upper-level. The strength of the upperlevel jet core produced a positive correlation with that of the dust storm. At the left-exit region of upper-level jet strong divergence would have developed due to the geostrophic adjustment process, and strong ascending motion being caused. The strong ascending motion in the mid troposphere conduced assistant forces to transport the dust from the lower to mid troposphere, although the dust may not have risen to the upper troposphere. Of course it also affected the dust storm indirectly by causing the cyclone to develop. 


\subsection{Two Super Dust Storm Centers}

During this dust storm period, there were two super dust storm areas with horizontal visibilities equal to $0 \mathrm{~m}$. One, on a small scale, was at Erjina station, while another, on a larger scale, covered a $60000 \mathrm{~km}^{2}$ area of Erlianhaote, Zhurihe, Shunite and Abaga stations (middle

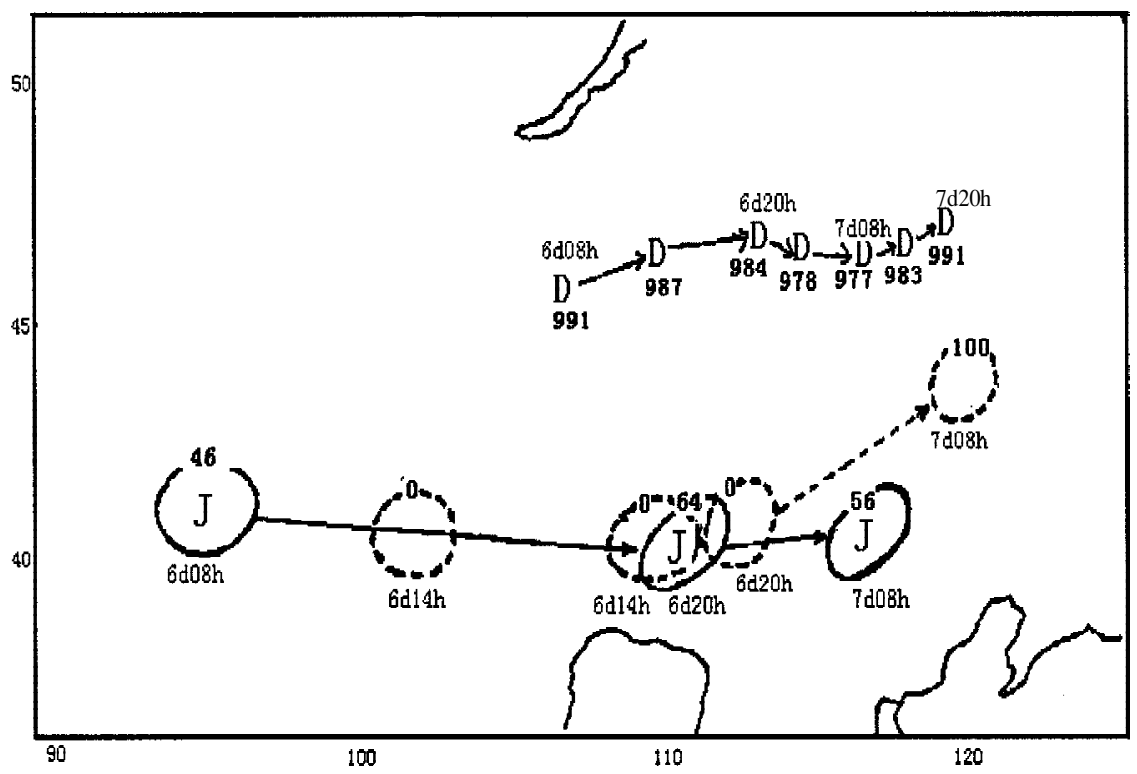

Fig. 9. The $300 \mathrm{hPa}$ jet-core (solid line), the minimal visibility (dashed line), and the position of cyclone center. The numbers marked above the solid and dashed lines are the maximal speed $\left(\mathrm{m} \mathrm{s}^{-1}\right)$ of the jet and the minimal visibility $(\mathrm{m})$, respectively, and the central pressure $(\mathrm{hPa})$ is marked below the cyclone center.

to northern IM). From 0825LST to 1617LST, April 6, the first super dust storm was caused mainly by the strong surface northwesterly wind with instantaneous wind speed reaching $29 \mathrm{~m} \mathrm{~s}^{-1}$ due to the cold front. Moreover, the center was located in the northwestern edge of the Badanjilin Desert, which is one of three primary sand sources in China. From 1400LST, April 6 to 0200LST, April 7, the second incidence was caused by the following factors: (1) strong surface wind; similar distribution between maximal surface wind speed and minimal visibility observed in stations was shown in Fig. 10. There are two centers where wind speed is larger than $18 \mathrm{~m} \mathrm{~s}^{-1}$ in Fig. 6. (2) A bare and loose ground surface; the second super dust storm area was in western Hunshadake sand lands, where the land surface had been denuded of vegetation. (3) Favorable force turbulence. The calculated Ri at 2000LST, April 6 in four stations of this area were 0. 


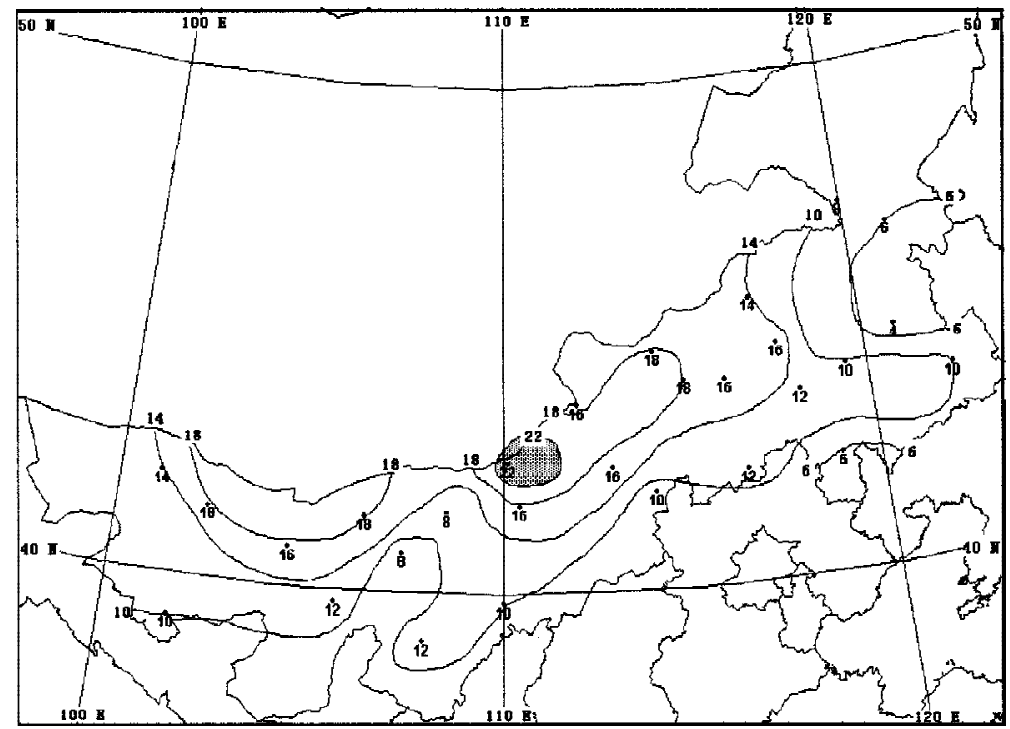

Fig. 10. The diagram of maximal wind speed from 1400LST, April 6 to 0200LST, April 7. (unit $\mathrm{m} \mathrm{s}^{-1}$, interval 2).

010, 0.016, 0.076 and 0.009, respectively; (4) Strong divergence-pumping in the upper troposphere assisted in forcing dust to be transported upward.

Compared with Fig. 1, the shape of isotach in Fig. 10 is quite similar to the iso-visibility mapping of the dust storm in Fig. 1. This means that the intensity of the dust storm was closely related to the wind, and that wind may be a key factor.

\section{CONCLUSIONS}

The following conclusions can be drawn from this study:

(1) The main sand source regions of this severe dust storm were the Badanjilin Desert in western IM, western Hunshandakend sand lands and the Gobi Desert in southern Mongolia.

(2) This dust storm process was a typical cyclonic dust storm, which was induced mainly by the intense development of a Mongolian cyclone rather than any other weather system such as a cold front (like the case of May 5, 1993). A remarkable characteristic of it was the semi-circular zonal dust storm areas.

(3) The formation of strong surface wind caused by the cyclonic cold front and secondary cold front, and by a strong meso-scale pressure gradient and allobaric gradient. Areas where strong surface wind formed closely accorded with the severe dust storm. Meanwhile, the 
strong meso-scale pressure gradient and allobaric gradient induced the severe prefrontal dust storm.

(4) After obtaining strong momentum from the strong surface wind, the dust was raised upward by strong turbulence in the PBL and ascending motion by the intensive development of a Mongolian cyclone. Meanwhile, divergence-pumping in the upper troposphere conduced an forces necessary to transplant the dust upwards.

Acknowledgements The authors are grateful to Prof. Chen S. J. of Peking University and to the comments from two anonymous reviewers, which improved the presentation of this paper considerably. We also thank Heilongjiang and Jilin Meteorological Bureaus for providing the data on the sand storm of April 7 - 8. This work is supported by The Major Project of National Science and Technology Grant (2000-k01-03-02 ).

\section{REFERENCES}

Barenblatt, G. I., and G. S. Goltsyn, 1974: Local structure of mature dust storms. J. Atmos. Sci., 31, 1917-1933.

Brazel, A. J., 1986: The Relationship of weather types to dust storm generation in Arizona (1965-1980) (J). J. Climatol., 6, 255-275.

Chen, C., 1980: The common meteorological and physical parameters table. Meteoro. publisher, Beijing, 9-11. (in Chinese)

Chen, J. P., Z. Wang, C. Y. Young, F. Tsai, I. C. Tsai, G. J. Wang, W. C. Shieh, H. W. Lin, and J. Y. Huang, and M. J. Lu2004: Simulations of Asian yellow dust incursion over Taiwan for the spring of 2002 and 2003.TAO, 15, 949-981.

Fang, Z. Y., 1997: Dust Storms in China, Meteor. Publisher, Beijing. (in Chinese)

Gamo, M., 1996: Thickness of dry convection and large-scale subsidence above deserts.Boundary Layer Meteor., 79, 265-278.

Hu, Y. Q., and T. Y. Guang, 1996: Mechanism Analysis on development of strong dust storm and formation of dry squall line and black storm. Plateau Meteor., 15, 178-185. ( in Chinese)

Jiang, X. G., J. G. Shen, J. T. Liu, and Y. S. Chung, 2003: Numerical simulation of synoptic condition on a severe sand dust storm. Water, Air, Soil Pollution, Spec. issue, 3,191212.

Lin, C. Y., S. C. Liu, Charles C. K. Chou, T. H. Liu, C. T. Lee, C. S. Yuan, C. J. Shiu, and C. Y. Young, 2004: Long-range transport of Asian dust and air pollutants to Taiwan.TAO, 15, 759-784.

Liu, J. T., and M. Q. Zheng, 1998: The climatology characteristic of black storms of North China. Meteor. Monthly, 24, 39-44. ( in Chinese)

Liu, J. T., Y. F. Yang, 1993: A study on the mechanism of the black storm occurring in a May 5 of 1993 in the northwestern regions of China. Quarterly J. Appl. Meteor., 7, 371-376. (in Chinese) 
Liu, K. Y., L. F. Hsiao, 2004: A composite comparative study of the dust events in Taipei and Beijing. TAO, 15, 983-998.

Liu, Y., 1998: A numerical simulation study on a sand transporting process. Chinese J. Atmos. Sci., 22, 905-912. (in Chinese)

Qian, Z. A., 1997: Investigation report and analysis on the super strong dust storm occurring on May 5, 1993. Chinese Dust Storm Study, 27-43. (in Chinese)

Qu, Z., 1994: Some apocalypses from the dust storm on May 05,1993.Drought Geography, 17, 63-67. (in Chinese)

Wang, C. C., C. T. Lee, S. C. Liu, and J. P. Chen, 2004: Aerosol characterozation at Taiwan's northern tip during ace-Asia. TAO, 15, 839-855.

Wang, S. G., 2000: Dust storm characteristics, forming reasons and prevention strategy. Development of Western Section: Seminar on meteorological technology and sustaining development, China Meteor. Soc.. (in Chinese)

Xu, G. C., 1979: The analysis on super strong dust storms in Ganshu province. Acta Meteor. Sinica, 34, 26-35. (in Chinese)

Yao, Y. F., 1998: Desert, People publisher of Inner Mongolia, Huhhot, 20-34. (in Chinese)

Yuan, C. S., C. C. Sau, M. C. Chen, M. H. Huang, S. W. Chang, and Y. C. Lin, and C. G. Lee, 2004: Mass concentration and size-resolved chemical composition of atmospheric aerosols sampled at the pencadores islands during Asian dust storm periods in the years of 2001 and 2002. TAO, 15, 857-879.

Zhang, X. L., L. S. Chen, and Y. S. Chung, 2003: Development of a severe sand-dust storm model and its application to northwest China. Water, Air, Soil Pollution., Spec. issue, 3, 173-190. 